\title{
Skin Graft in the Surgery Department "B" of the CHU du Point "G" about 50 Cases
}

\section{Mahamadou Coulibaly ${ }^{1,2 *}$, Bréhima Bengaly ${ }^{1,3}$, Drissa Ouattara ${ }^{3}$, Traoré Drissa ${ }^{1,3}$, Diallo Siaka ${ }^{3}$, Souleymane Sanogo ${ }^{3}$, Birama Togola1,3, Nouhoum Ongoiba1,3}

${ }^{1}$ Faculty of Medicine, University of Science, Technique and Technologies of Bamako, Bamako, Mali

${ }^{2}$ Department of Surgery, Koutiala Hospital, Bamako, Mali

${ }^{3}$ Department of Surgery, University Hospital Center Point G, Bamako, Mali

Email: *cmahamadou38@yahoo.fr

How to cite this paper: Coulibaly, M., Bengaly, B., Ouattara, D., Drissa, T., Siaka, D., Sanogo, S., Togola, B. and Ongoiba, N. (2020) Skin Graft in the Surgery Department "B" of the CHU du Point "G" about 50 Cases. Surgical Science, 11, 187-193. https://doi.org/10.4236/ss.2020.117021

Received: May 22, 2020

Accepted: July 10, 2020

Published: July 13, 2020

Copyright (C) 2020 by author(s) and Scientific Research Publishing Inc. This work is licensed under the Creative Commons Attribution International License (CC BY 4.0).

http://creativecommons.org/licenses/by/4.0/

\begin{abstract}
Aim: To analyze the practice of skin grafting in the surgery department "B" of the CHU of Point "G" in Bamako. Patients and Methods: This was a retrospective and prospective study carried out between 1980 and 2014, covering all patients who underwent a skin graft and hospitalized. It covered all patients who underwent a skin transplant and were hospitalized in the department during the study period. Result: There were 50 patients including 25 women and 25 men. The mean age was $25.2 \pm 19$ years. The average duration of lesion evolution was 1 year. The lesions to be grafted were located in the lower limbs in $60 \%$. The average area of substance loss was $13.2 \mathrm{~cm}^{2}$. The indication for skin graft was asked for loss of substance following scar bridles in $40 \%$, ulcerative-necrotic wounds of infectious or traumatic origin (32\%), malignant skin tumor (14\%). In pathology, there were 5 cases of malignant melanoma and 2 cases of squamous cell carcinoma. Thin skin grafting was the most used technique (62\%). The postoperative follow-ups were simple in $94 \%$. There were 3 cases of graft necrosis. The average length of hospital stay was 28 days. The esthetic result was judged satisfactory in $84 \%$ of the cases $(\mathrm{n}=$ $42)$, average in $14 \%$ of the cases $(n=7)$ and unsatisfactory in $2 \%$ of the cases $(\mathrm{n}=1)$. The sensitivity was good in 36 patients $(72 \%)$, average in 12 patients (24\%) and poor in 2 patients (4\%). Conclusion: They mainly affect young people. The reduction of accidents on the public highway, good management of burn injuries, wounds and good hygiene of the population will considerably reduce the rate of its affections.
\end{abstract}

\section{Keywords}

Skin Graft, Surgery, Postoperative Operations 


\section{Introduction}

Skin grafting is a surgical procedure which consists in implanting a graft or a flap of skin collected at a location on the patient's body [1]. Skin grafting is for patients with significant loss of substance with a variety of etiology. In France in 1992 in Professor Servant's plastic reconstructive and aesthetic surgery department, out of 1190 procedures performed, $698 \%$ or $58 \%$ represented dermatological lesions which required a skin graft [2]. In Mali, according to Bah's study [3] carried out at the CNAM (former Marchoux Institute) in 2008, skin grafting represented $16.16 \%$ of surgical treatment. According to Dakouo E [4] in Mali in 2008 in a study carried out on the cost of necrotic ulcers, $62 \%$ of patients benefited from a thin skin transplant. At Point "G" University Hospital, the "B" surgery department, in addition to its visceral surgery activities, has been practicing skin grafting for several years. However, no work has been undertaken on this surgical activity. This is what motivated this work, the purpose of which was to analyze the practice of skin grafting in the surgery department " $\mathrm{B}$ " of the $\mathrm{CHU}$ of Point "G" in Bamako.

\section{Patients and Methods}

This was a retrospective study carried out from 1980 to 2014 in the surgery department B of CHU du Point G. It focused on all patients who underwent a skin graft and hospitalized in the department during the study period. Were not included in this study, patients whose lesions did not require a skin transplant and patients whose medical records were incomplete. A detailed database was validated by the hospital's scientific committee, which provided information on socio-demographic data, duration of development, diameter of lesions, skin graft indications, grafting technique and consequences operating. For this we used the patient's medical file, the consultation register, the notebooks of the operating report. The comparison test used was the Chi-square test and the significance of the difference was determined by a probability $\mathrm{p}<0.05$.

The lesions that required skin grafting were sequelae of thermal burns, ulcerative necrotic wounds and skin ulcers. It was also performed after removal of keloids, cleft lips and malignant tumors. The surface of the lesions was between 5 and $30 \mathrm{~cm}$. The average duration of lesion evolution was 1 year. The sites of the graft sample were the inguinal fold, the anterior and internal aspect of the thigh and the anterior aspect of the arm. The donor areas were sutured with intradermal overlock. The grafts were of thin and total skin; they have been degreased and put in salted serum before fixing. The graft suturing at the donor site was done by separate stitches with monocryl. The fatty dressing was applied to the recipient area in all patients. The first postoperative dressing was performed on the fifth day but in three patients it was done before because of the stain. Physical rehabilitation began in patients from the third week and consisted of gentle mobilization, palpate-rolling movements to soften the skin. Patients were seen once a week until healing and once every 3 months. The purpose of this post- 
operative monitoring was to assess the aesthetic result and the quality of the sensitivity (thermal, tactile and pain relief).

The aesthetic result was judged:

- Satisfactory: if the texture and coloring of the grafts totally resemble other parts of the body.

- Medium: if the texture and coloring of the grafts partially resemble other parts of the body.

- Unsatisfactory: if the texture and coloring of the grafts does not look like other parts of the body.

The quality of the sensitivity was judged:

- Good: if two of the three sensitivities were found.

- Medium: if one of the three sensitivities was found.

- Bad: if none of the sensitivities are found.

\section{Results}

During the study period, we identified 50 patients who underwent a skin graft, which represented $0.20 \%$ of the surgical procedures of the " $\mathrm{B}$ " surgery department. He had as many women as men in this study with a sex ratio of 1 (Table 1). The mean age was $25.25 \pm 19$ years and extremes of 2 years and 80 years. The lesions to be transplanted were located in the lower limbs in $60 \%$ of the cases ( $\mathrm{n}$ $=30)$, the upper limbs in $26 \%$ of the cases $(n=13)$, the thorax $(12 \%, n=6)$ and the head $(2 \%, \mathrm{n}=1)$. Scar bridles were the most frequent reason for consultation with $36 \%$. The average duration of lesion evolution was 1 year with the extremes of 2 days and 19 years. Anti-inflammatory drugs were the most frequently prescribed drugs before the surgical consultation with $32 \%$ of the cases. The majority of patients (42\%) had no specific history. History of skin graft was observed in $6 \%$ of patients $(n=3)$. The majority of the patients had a good general condition with a karnofsky index evaluated at $80 \%$ in 30 cases or $60 \%$ of the cases. The functional signs were pain, pruritus, tingling and limitation of movement in $92 \%$ of the cases $(n=46)$. On physical examination there was pain in $52 \%$ of cases $(n=26)$, suppuration in $32 \%$ of cases $(n=16)$, local heat in $20 \%$ of

Table 1. Distribution of patients by sex and lesions.

\begin{tabular}{ccccc}
\hline Lesions & Male & Female & Effective & $\%$ \\
\hline Scar bridles & 12 & 8 & 20 & 40.0 \\
$3^{\text {rd }}$ degree burn & 1 & 2 & 3 & 6 \\
Ulcerative-necrotic wound & 9 & 7 & 16 & 32 \\
keloid & 0 & 2 & 2 & 4 \\
Malignant tumor & 2 & 5 & 7 & 14 \\
Buruli ulcer & 1 & 0 & 1 & 2 \\
Cleft lip + wound & 0 & 1 & 1 & 2 \\
Total & 25 & 25 & 50 & 100.0 \\
\hline
\end{tabular}


cases $(n=10)$ and skin swelling in $18 \%$ of cases $(n=9)$. The consistency of the lesion was hard in $30 \%$ of cases $(n=15)$, soft in $12 \%$ of cases $(n=6)$ and firm in $4 \%$ of cases $(\mathrm{n}=2)$. When measured, the average area of substance loss was $13.25 \mathrm{~cm}^{2}$ and extremes of $3 \mathrm{~cm}^{2}$ and $30 \mathrm{~cm}^{2}$. Limb radiography was performed in $70 \%$ of cases $(\mathrm{n}=35)$ and no bone lesion was found. Ultrasound of the lesion was done in $18 \%$ of our patients $(n=9)$ and it objectified keloids $(4 \%, n=2)$ and the malignant skin tumor $(14 \%, n=7)$.). The biopsy performed for suspected malignancy $(n=7)$ revealed 5 cases of malignant melanoma and 2 cases of squamous cell carcinoma. Computed tomography (CT) was searched for secondary location in $8 \%$ of cases $(n=4)$. The indication for skin graft was asked for loss of substance following scar bridles in $40 \%$ of cases $(n=20)$, ulcerative-necrotic wounds of infectious or traumatic origin in $32 \%$ of cases $(n=16)$ and malignant skin tumor $(14 \%, n=7)$ (Table 1$)$. For malignant tumors, only one patient received neoadjuvant chemotherapy. All patients were operated on under general anesthesia. Dermo-epidermal skin autograft has been performed in all our patients. The surgical technique performed was thin skin grafting in $62 \%$ of patients $(n=31)$, total skin grafting in $18 \%(n=9)$, excision associated with total skin grafting in 6 cases, ie $12 \%$, the excision associated with the thin skin graft in 3 cases, ie $6 \%$ and the mixed total and thin skin graft in 1 case, ie $2 \%$ (Figure 1). The postoperative follow-up was simple in $94 \%$ of the cases. We noted graft necrosis in 3 patients (6\%). These grafts were partially necrotic in 2 patients and totally in 1 patient. These necroses were secondary to infection in 2 patients and ischemia in 1 patient. The management was an ablation of the necrotic grafts. The nine patients who underwent a total skin transplant healed completely, 29 of the 31 patients who underwent a thin skin transplant healed. The only patient who had had a combination skin graft healed completely. The average length of hospital stay was 28 days with extremes of 4 and 90 days. The

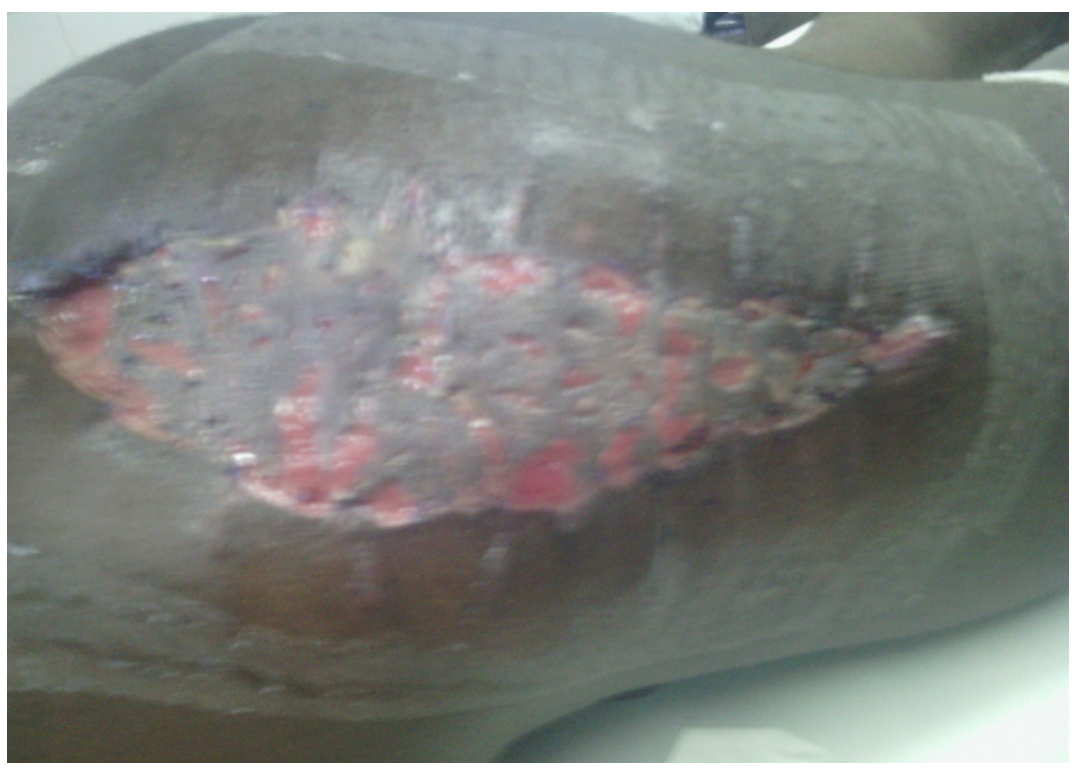

Figure 1. Photo of thin skin graft of the right buttock. 
esthetic result was judged satisfactory in $84 \%$ of the cases $(n=42)$, average in $14 \%$ of the cases $(n=7)$ and unsatisfactory in $2 \%$ of the cases $(n=1)$. The sensitivity was good in 36 patients (72\%), average in 12 patients (24\%) and poor in 2 patients (4\%).

\section{Discussions}

Among the 50 cases recorded, there were as many women as men with a sex ratio of 1 . Bah in Mali brought a higher female rate $(1.2, p<0.5)$ [3]. This difference would be related to the framework of his study which was carried out in a dermatology department and focused on all surgical dermatoses whose most common etiology was keloids of the ear due to frequent ear breakthroughs in this population. The average age of our patients ( 25.2 years) is similar to that of the African authors [3] [5] but lower than that of Mostig in Italy (74 years, $p=$ 0.0025) [6]. The youth of the African population could explain the difference. Depending on the gross appearance of the lesions, scar bridles and ulcerative necrotic wounds were the most frequent. The high rate of these lesions is linked to poor initial management of burn and wound lesions. Like some authors, we have found that these lesions are frequent on the lower limbs [4] [7]; This result differs from that of Caron in France [8] (Table 2). This difference could be explained by the higher frequency of vascular pathologies in Western countries, in particular venous, causing most ulcers. $14 \%$ of the lesions were malignant tumors composed of malignant melanoma and squamous cell carcinoma. The same rate is observed in other African series [9] [10]. The most common surgical technique was one-step skin grafting as the main indications for grafting were scar bridles and ulceronecrotic wounds. Other surgical techniques included resection with total skin graft, resection with thin skin graft and total skin graft. Sometimes you can combine several types of transplant at the same time. This is why in the same patient a mixed total skin and thin skin graft was performed. The indication for skin graft also depends on the site of the lesion. In the hand, it is the total skin graft that is most often indicated. Reason why in Morocco, EL Mazay et al. brought a higher total skin graft rate (76\%) because his study focused on skin graft in hand burns [11] (Table 3). Dermo-epidermal skin autograft has

Table 2. Seat of lesions according to the authors.

\begin{tabular}{|c|c|c|c|c|c|c|c|c|}
\hline Authors & Leg & Thigh & Foot & Arms & Forearm & Hands & Thorax & Head \\
\hline \multirow{2}{*}{$\begin{array}{c}\text { Cornet L Cote } \\
\text { d'Ivoire } 1999 \text { [7] }\end{array}$} & $38.80 \%$ & $38.80 \%$ & $5 \%$ & $5 \%$ & $2.40 \%$ & $5 \%$ & $5 \%$ & \\
\hline & $\mathrm{P}=0.57$ & $\mathrm{P}=0.57$ & $\mathrm{P}=0.03$ & $\mathrm{P}=0.03$ & $\mathrm{P}=0.31$ & $\mathrm{P}=0.03$ & $\mathrm{P}=0.30$ & \\
\hline \multirow{2}{*}{ Caron France 2003 [8] } & $83 \%$ & & $17 \%$ & & & & & \\
\hline & $\mathrm{P}=0.02$ & & $\mathrm{P}<0.05$ & & & & & \\
\hline \multirow{2}{*}{ Dackou Mali 2008 [4] } & $51.90 \%$ & $36.70 \%$ & $44.30 \%$ & $10.10 \%$ & $10.10 \%$ & $8.90 \%$ & $5.10 \%$ & \\
\hline & $\mathrm{P}=0.72$ & $\mathrm{P}=0.44$ & $P=0.36$ & $\mathrm{P}=0.10$ & $\mathrm{P}=0.10$ & $\mathrm{P}=0.08$ & $\mathrm{P}=0.05$ & \\
\hline Our study & $60 \%$ & & & $20 \%$ & & $6 \%$ & $12 \%$ & $2 \%$ \\
\hline
\end{tabular}


Table 3. Total skin graft according to the authors.

\begin{tabular}{ccc}
\hline Authors & Total skin graft & Percentage \\
\hline AL Mazay Maroc 2007 & & \\
$\mathrm{N}=152$ & $76 \%$ & $\mathrm{P}<0.05$ \\
Our series & $12 \%$ & \\
\hline
\end{tabular}

been performed in all our patients. This technique is used with variable frequencies in the literature [7] [10] [11] [12]. The cure rate differs depending on the operative indication and the operative technique. All of our patients who benefited from a total skin transplant completely healed, $94 \%$ of those who benefited from thin skin transplants healed. The only patient who had had a combination skin graft healed completely. The average length of hospital stay was 28 days according to our study, 23 days according to Souissi and AL in Tunisia ( $p=0.65)$ [13] and 69 days according to Dackouo in Mali $(\mathrm{p}=0.53)$ [4]. The limitation of our surgical activity by the insufficiency of the technical platform, the irregularity of the patients in the follow-up, the refusal of the surgical act and the low income were handicaps in our study. However, the quality of the results obtained with the acts performed deserves to be supported and encouraged. Furthermore, the drawback of retrospective studies is the loss of certain data or even of the entire file, which limited our results.

\section{Conclusion}

Lesions requiring skin grafting are more and more frequent conditions in our department. They mainly affect young subjects. The reduction of accidents on the public highway, good management of burn injuries, wounds and good hygiene of the population will considerably reduce the rate of its affections.

\section{Author Contributions}

All authors have read and approved the final version of the manuscript.

\section{Conflicts of Interest}

The authors declare no conflicts of interest regarding the publication of this paper.

\section{References}

[1] Henry, M.M. and Thompson, J.N. (2004) Clinical, Technical and Practical Surgery: Translation of the 1st American Edition by Jean Miliaire Free University of Brussels, Brussels, 674-677.

[2] Prénaux, J. (1992) Dermatology Surgery. In: Encyclopedia, Med. Chir. Dermatology. 920A 10-1992.14.

[3] Bah, M.O. (2008) The Practice of Dermatological Surgery at the Venous Dermatology Unit (CNAM). Thesis Medicine, University of Bamako, Bamako.

[4] Dakouo, E. (2008) Necrotic Ulcers in the General and Pediatric Surgery Depart- 
ments of the CHU Gabriel Touré. Thesis, Medicine-University of Bamako, Bamako.

[5] Kane, A., Niang, O.S., Dieng, M.T., Diallo, M.N. and Diaye, B. (2007) Tropical Leg ulcers, Clinical and Epidemiological Aspects in Senegal. Annales de Dermatologie et de Vénéréologi, 134, 863-873

[6] Mostig, G., Iabichala, M.I., Picern, P.A. and Stefani, A. (2005) Homologous Skin Grafts in the Treatment of Phlebostatic Ulcers. Phlebology, 58, 41-48.

[7] Cornet, L., Richar, M.K., Dick, R. and Djeha, D. (1990) Skin Ulcers with Atypical Mycobacteria and Their Treatment by Plastic Surgery. Black African Medicine, 37, 276-282.

[8] Caron, J.M., Roth, B. and Giullaume, J.G. (2007) Prevalence and Management of Chronic Wounds in 14 Geriatric Institutions of the Haut-Rhin. Annales de Dermatologie et de Vénéréologie, 134, 645-651. https://doi.org/10.1016/S0151-9638(07)91825-6

[9] Tuyns, A.J. (1971) Skin Cancers in Africa and Worldwide. Medicine of Black Africa.

[10] Tossou, A. (1992) Dermatological Pathology Observed in the Dermato-Venerology Department of the Cotonou Hospital and University Center. Thesis of Medicine Cotonou.

[11] EL Mazaouz, S., Fejjal, N., Cherck, A., Belfqih, R., Gharib, L. and Abbassi, A. (2010) Skin Grafting in the Treatment of the after Effects of the Burnt Hand. about 152 Cases. In the Plastic Surgery Department of the Ibn Sina University Hospital Center, Rabat, Morocco from 1998-2007.

[12] Mseddi, M., Khenekhem, M. and Daoud, L. (2005) Leg Ulcer, Study of 210 Cases. Maghreb Médical, 25, 79-81.

[13] Souissi, A., Ben, N., Tekaya, N.B., Youssef, M., Cherif, F., et al. (2005) Ulcères de Jambe: Étude Clinique et Épidémiologique des Malades Hospitalisés à Tunis. Annales de Dermatologie et de Vénéréologie, 132, 1010-1012.

https://doi.org/10.1016/S0151-9638(05)79570-3 